\title{
Antibiotic Treatment and Survival of Nursing Home Patients With Lower Respiratory Tract Infection: A Cross-National Analysis
}

\author{
Robin L. Kruse, $P b D^{1}$ \\ David R. Mebr, MD, MS ${ }^{1}$ \\ Jenny T. van der Steen, $P b D^{2,3,4}$ \\ Marcel E. Ooms, $M D, P b D^{2,3}$ \\ Richard W. Madsen, $P b D^{5}$ \\ Asbley K. Sherman, $M A^{5}$ \\ Ralph B. D'Agostino, $P b D^{6}$ \\ Gerrit van der Wal, MD, $P b D^{3,4}$ \\ Miel W. Ribbe, $M D, P b D^{2,3}$ \\ 'Department of Family and Community \\ Medicine, University of Missouri-Columbia, \\ Columbia, Mo \\ ${ }^{2}$ Department of Nursing Home Medicine \\ of the VU University Medical Center, \\ Amsterdam, The Netherlands \\ ${ }^{3}$ Institute for Research in Extramural \\ Medicine (EMGO Institute) of the VU \\ University Medical Center, Amsterdam, \\ The Netherlands \\ ${ }^{4}$ Department of Public and Occupational \\ Health of the VU University Medical \\ Center, Amsterdam, The Netherlands \\ ${ }^{5}$ Biostatistics Unit, Office of Medical \\ Research, University of Missouri-Columbia, \\ Columbia, Mo \\ ${ }^{6}$ Mathematics and Statistics Department, \\ Boston University, Boston, Mass

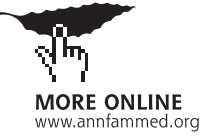

Conflicts of interest: none reported

\section{CORRESPONDING AUTHOR}

Robin L. Kruse, $\mathrm{PhD}$

Department of Family and Community Medicine

University of Missouri-Columbia School of Medicine

Columbia, MO 65212

kruser@health.missouri.edu

\begin{abstract}
PURPOSE Although lower respiratory tract infections are a leading cause of death in frail elderly patients, few studies have compared treatments and outcomes. We assessed the effects of different antibiotic treatment strategies on survival of elderly nursing home residents with lower respiratory tract infections in the United States and the Netherlands, where treatment approaches are quite different.
\end{abstract}

METHODS We combined data from 2 prospective cohort studies of lower respiratory tract infections conducted in 36 nursing homes in the United States and 61 in the Netherlands. We included residents whose infections were treated with antibiotics: 806 in the United States and 415 in the Netherlands. Outcome measures were 1-month and 3-month mortality. We used logistic regression to adjust for differing illness severity.

RESULTS Dutch residents had higher mortality than US residents ( $28.1 \%$ vs $15.1 \%$ at 1 month, respectively; $P<.001$ ). After adjusting for illness severity with logistic regression, the differences between the Dutch and US populations were not significant (odds ratio $1.34 ; 95 \%$ confidence interval, 0.94-1.90). Predicted mortality was overestimated for more severely ill US residents at 1 month but not at 3 months. No antibiotic regimen was consistently associated with increased or decreased mortality.

CONCLUSION Despite differences in illness severity and treatment, adjusted mortality did not differ between the 2 countries. Although we cannot exclude a short-term survival benefit from more aggressive treatment in the United States, differences in baseline health appear prognostically more important than the type of antibiotic treatment.

Ann Fam Med 2005;3:422-429. DOI: 10.1370/afm.389.

\section{INTRODUCTION}

$\mathrm{N}$

Ursing home residents frequently develop lower respiratory tract infections, mostly pneumonia and bronchitis, ${ }^{1-5}$ with estimated 30-day mortality from pneumonia or lower respiratory tract infection varying between $10 \%$ and $30 \%{ }^{3,6-9}$ Because meaningful cultures from specimens are rarely obtained in practice, ${ }^{10,11}$ antibiotic treatment is usually empiric. ${ }^{10-12}$ Despite guidelines from authoritative groups ${ }^{13-15}$ however, little evidence supports any specific regimen. Naughton and colleagues ${ }^{16}$ found no difference in mortality between residents treated initially with either oral or intramuscular antibiotics. In a second study, adherence to an antibiotic guideline did not affect mortality. ${ }^{17}$ In a few small trials from the late 1980s or early 1990s, researchers found effectiveness of ceftriaxone or ciprofloxacin to be equal when compared with similar antibiotics. ${ }^{18-21}$

The ideal study design to test different regimens would be a randomized controlled trial ${ }_{i}$ practical and ethical difficulties make such a study unlikely. Consequently, we must rely on data from observational studies, attempting to control for differences between treatment groups. Two large, 
concurrent studies of lower respiratory tract infections acquired by residents in nursing homes in the United States and the Netherlands provided the opportunity to examine how antibiotic treatment affected outcomes. ${ }^{22,23}$ In the US study, 30-day mortality was associated with 8 variables in a multivariable logistic model: blood urea nitrogen, white cell count, low absolute lymphocyte count $\left(<0.8 \times 10^{9} / \mathrm{L}\right)$, lower body mass index, pulse rate, activities of daily living status, male sex, and deterioration in mood. ${ }^{22}$ One-week mortality in Dutch residents who were treated with antibiotics was related to 7 variables in multivariable logistic regression: respiratory rate, pulse rate, dependency in eating, recent increase in discomfort, decreased alertness, inadequate fluid intake, and recent occurrence of decubitus ulcers. ${ }^{23}$

Compared with treatment in the United States, hospitalization, use of intravenous antibiotics and multiple antibiotic regimens, intravenous fluids, and feeding tubes are relatively rare in the Netherlands. 3,7,8,22,24-26 Such wide differences in care provide a natural experiment of the relationship of treatment and outcomes. We hypothesized that although there would be little overall difference in 1 - and 3-month mortality among regimens, we would identify a group of residents for whom more aggressive therapy is more effective.

\section{METHODS}

\section{Patient Recruitment and Data Collection}

The Missouri LRI (lower respiratory tract infection)

Study prospectively enrolled residents of 36 nursing homes in central Missouri and the St. Louis area between August 1995 and September 1998. Trained project nurses evaluated residents who had symptoms compatible with a lower respiratory tract infection. Diagnosis of lower respiratory tract infection was determined according to a standardized definition that required either (1) 3 of 6 signs or symptoms of lower respiratory tract infection (eg, cough, purulent sputum production) or general illness (eg, fever or worsening mental or functional status); or (2) 2 signs and symptoms with a chest radiograph interpreted as showing probable pneumonia. To avoid including an exacerbation of congestive heart failure or chronic obstructive pulmonary disease, we also required either probable pneumonia or a temperature of at least $38^{\circ} \mathrm{C}$ in association with those chronic conditions. Details of identification and evaluation are described elsewhere. ${ }^{22,27}$ About two thirds of residents had possible or probable pneumonia determined by chest radiographs. Those found to have a lower respiratory tract infection (1,409 episodes in 1,044 residents) were observed for a minimum of 3 months after evaluation. Data were collected from several sources, includ- ing nurse evaluations and medical record information. Institutional review boards at the University of MissouriColumbia School of Medicine and Washington University School of Medicine approved the protocol.

The nationwide Dutch Pneumonia Study was conducted in psychogeriatric units in 61 nursing homes between October 1996 and July 1998. ${ }^{23}$ Enrollment criteria included psychogeriatric disease $(97 \%$ had dementia), facility residence for at least 4 weeks, and pneumonia diagnosed by the attending physician. The investigators prospectively identified 706 consecutive residents with a diagnosis of pneumonia. Consistent with Dutch practice, attending physicians belonged to the permanent staff of the nursing home and cared for patients daily. ${ }^{28}$ They rarely ordered chest radiographs or blood tests. In contrast with the US study, Dutch residents were enrolled only once. The physicians caring for patients recorded their data on standardized forms at several points during 3 months of follow-up. The Medical Ethics Committee of the VU University Medical Center, Amsterdam, approved the study protocol.

\section{Selection of Residents}

For this analysis, we included US and Dutch residents aged 70 years or older whose condition explicitly met the US study definition of a lower respiratory tract infection and who received antibiotic therapy. Antibiotic therapy was defined as any antibiotic started from 2 days before diagnosis until 5 days after diagnosis. We excluded residents who did not receive antibiotics because they were dissimilar in the 2 countries. Dutch residents who did not receive antibiotics were quite ill and almost always receiving palliative care; in contrast, many US residents who did not receive antibiotics were not very ill. ${ }^{29,30}$ Among residents with dementia who did not receive antibiotics, 1 -month mortality was strikingly different for Dutch and US residents, $90.2 \%$ and $17.5 \%$, respectively. ${ }^{30}$

Only the first episode of illness was included for US residents with multiple enrollments. We excluded 193 of 1,044 US residents who did not receive antibiotics within the specified time frame and 45 who were younger than 70 years, leaving 806 for this analysis. Of the original 706 Dutch residents, we excluded 127 who did not meet the US study definition, 5 whose diagnosis was revised (to non-lower respiratory tract infection) after enrollment, 141 who did not receive antibiotics or whose antibiotic status was unknown, 16 who were younger than 70 years, and 2 with unknown age. We included the remaining 415 Dutch residents in the analysis.

\section{Variables}

We measured variables relative to the time of the treatment decision (in the Dutch study) or the time of the resident's evaluation (in the US study). Hereafter, we 
refer to this as "the time of diagnosis" for both studies. Mortality was noted for at least 3 months after diagnosis. Selection of variables and definitions have been described in detail elsewhere. ${ }^{26}$ We defined dehydration as either poor skin turgor or dry mucous membranes noted at the time of diagnosis. Activities of daily living (ADL) performance was measured using the 5-level self-performance items from the Minimum Data Set $(\mathrm{MDS})^{31}$ in the US study and the 4-level Bedford Alzheimer Nursing Severity-Scale (BANS-S) ${ }^{32}$ items in the Dutch study. To create common ADL measures for self-performance of eating, walking, and dressing, we collapsed the middle categories to create 3 -level items scored as 0 (independent), 1 (requires assistance), or 2 (fully dependent). The sum of these 3 scores was used to rate overall ADL performance. Our definition of severe dementia included both cognitive and ADL impairment. ${ }^{26}$ We defined study residents as having severe dementia if they had at least 4 of 6 possible points on the overall ADL scale and were severely cognitively impaired (a score greater than 15 on the BANS-S for Dutch residents or a score of 5 or 6 on the CPS for US residents).

\section{Analysis}

We performed all statistical analyses with SAS for Windows. ${ }^{33}$ To determine a relationship between antibiotic choice and mortality, we first created a statistical model to control for illness severity. After combining the data sets, we began with bivariate analyses to determine which variables were related to mortality and nationality. For the rare missing values (mostly less than $4 \%$ ), we imputed the mean for continuous variables and the mode for categorical data. To avoid disproportionate influence of extreme outliers, we set pulse rates below 60 beats per minute at 60 beats per minute and pulse rates above 140 beats per minute at 140 beats per minute. Similarly, we truncated respiratory rates above 50 breaths per minute at 50 breaths per minute.

Beginning with residents' characteristics, we developed logistic regression models for 1 - and 3-month mortality. Because the purpose of the models was to control for confounding, we did not limit the number of variables in the models and retained variables of marginal statistical significance $(.05<P<.10)$ that we believed were clinically important. We also included variables that were not statistically significant if they were important confounders and tested several quadratic terms. After developing these initial models, we tested facility size and the physician's age and years of experience in the models. Finally, we included a dichotomous nationality variable (Dutch $=1$, US $=0$ ). We explored whether variables performed consistently across the 2 studies by interacting variables by nationality and testing the inter- action terms in the final models. Stratifying by deciles of predicted mortality, we examined actual mortality for US and Dutch residents to determine whether model performance was consistent in both populations.

We then examined initial antibiotic therapy relative to mortality. Antibiotics were divided into several classes based on the clinical relevance and prevalence of individual agents. For Dutch residents, we further consolidated the classes because some antibiotics were rarely prescribed in the Netherlands.

We found that antibiotic use differed between the 2 countries, not only in the agents used but in how their use related to illness severity (Figure 1). The data are therefore incompatible with the simple approach of adding a design variable representing classes of antibiotics to the basic logistic models that control for resident and facility characteristics. Instead, to test whether mortality differed by antibiotic choice, we stratified residents by ranges of illness severity calculated from our logistic models. Because mortality risk was unevenly distributed in the 2 populations, we used clinically meaningful cutoff values that would place a reasonable number of residents in each group. Because of the disparity in antibiotic treatment, we examined Dutch and US residents separately. After controlling for mortality risk, we used the Cochran-MantelHaenszel statistic of general association ${ }^{34}$ to test for a consistent relationship between mortality and antibiotic treatment over all strata. Fisher's exact test was used to determine whether antibiotic treatment had different associations with mortality within different risk strata.

\section{RESULTS}

\section{Description of Residents and Treatments}

Compared with US residents, Dutch residents were more severely ill overall, more severely ADL dependent, and more often had severe dementia; however, they had fewer comorbidities (Table 1). Unadjusted mortality was substantially higher for Dutch residents than US residents at both 1 month $(28.1 \%$ vs $15.1 \%$, respectively; $P<.001)$ and 3 months $(36.5 \%$ vs $24.8 \%$, respectively; $P<.001$ ).

Most Dutch residents $(71.8 \%)$ were treated with oral amoxicillin or amoxicillin/clavulanate; only $15.3 \%$ of US residents received these regimens (Table 1 ). US residents most frequently received cephalosporins (37.6\%). Thirty-nine different antibiotic agents were used in the United States compared with 15 in the Netherlands. Forty-six (11.1\%) Dutch residents received intramuscular ampicillin or amoxicillin, followed by oral amoxicillin; this combination was not used in the United States. Other than that combination, only 1 Dutch resident received 2 antibiotics (cefuroxime and gentamicin) com- 


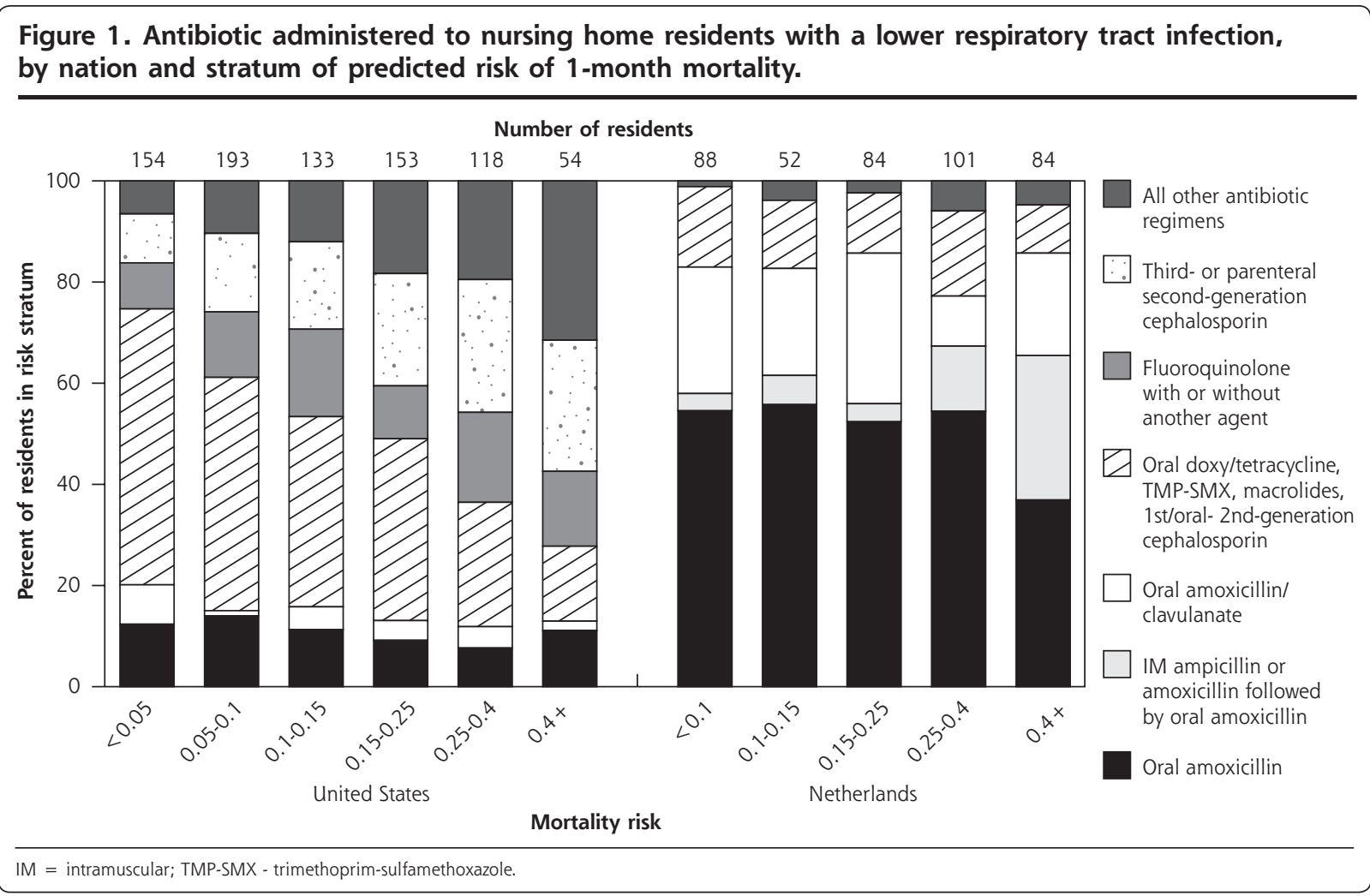

pared with $14.5 \%$ of US residents (for example, $9.2 \%$ received a third-generation or parenteral second-generation cephalosporin with another agent). US residents received parenteral antibiotics more often than Dutch residents $(32.1 \%$ vs $12.8 \%$, respectively, $P<.001)$.

Patterns of antibiotic treatment differed between nations across mortality risk derived from our logistic model described below (Figure 1). As mortality risk increased, treatment of US residents with doxycycline, tetracycline, macrolides, or trimethoprim-sulfamethoxazole declined while treatment with third-generation or parenteral second-generation cephalosporins increased. In contrast to the United States, amoxicillin was commonly used across all levels of risk in the Dutch population. The combination of intramuscular ampicillin or amoxicillin followed by oral amoxicillin was given to Dutch residents with higher mortality risk.

Only 1 Dutch resident $(0.2 \%)$ but almost one third (30.4\%) of US residents were hospitalized. For US residents, hospitalization increased with mortality risk, from $15.6 \%$ of residents with less than $5 \%$ mortality risk, to $56.4 \%$ of residents with a mortality risk of $40 \%$ or more. More than two thirds (68.2\%) of hospitalized residents received parenteral antibiotics compared with $16.4 \%$ of residents who were not hospitalized. Rehydration therapy was 10 times more common in the United States (34.5\%) than in the Netherlands (3.0\%) in the month following diagnosis $(P<.001)$.

\section{Mortality Models}

Table 2 shows logistic models for 1 - and 3-month mortality. For 1 -month mortality, several indicators of acute illness were associated with increased risk of mortality, as were impaired self-performance of eating and walking, male sex, increased age, and Parkinson's disease. Age was of borderline significance $(P=.064)$, but we retained it in the model to help control for confounding. Model discrimination was good (c statistic = 0.765 ), with good calibration over the range of mortality risk (Hosmer-Lemeshow goodness-of-fit, $P=.895$ ).

The 3 -month model also included 2 variables reflecting an increasing number of chronic health problems (bladder continence and congestive heart failure) and respiratory rate, another acute illness indicator, which was of borderline significance $(P=.096)$; respiratory rate was not significantly associated with 1 month mortality $(P=.302)$. Discrimination (c statistic $=0.737$ ) and calibration (Hosmer-Lemeshow goodnessof-fit, $P=.635$ ) were good.

Despite the increased illness severity of the Dutch residents compared with US residents, Dutch nationality was not independently significant when added to either the 1 - or 3 -month models (odds ratio [OR] $1.34,95 \%$ confidence interval $[\mathrm{CI}] .94-1.90$; and OR $1.20,95 \% \mathrm{CI}, 0.87-1.66$, respectively). There were no significant interactions between nationality and other variables. For low to moderately high risk of 1 -month 
mortality ( $0 \%$ to $25 \%$ ), predicted and actual mortality were quite similar between the 2 populations (Figure 2). At higher levels of predicted mortality, however, the model overpredicted mortality for US residents and underpredicted mortality for Dutch residents. This disparity was not evident at 3 months.

\section{Treatment Effects}

After stratifying by mortality risk, the overall association between antibiotic agent and mortality for Dutch residents was not statistically significant at 1 month $(P=.143)$, but it was statistically significant at 3 months $(P=.020)$, indicating that mortality is not distributed evenly between antibiotics after adjusting for mortality risk. Looking within individual risk strata (available in Supplemental Table 1 online at: http:// www.annfammed.org/ cgi/content/full/3/5/422/

I DC1), however, there was no statistically significant association between a particular antibiotic and mortality at any level of risk for Dutch residents at either 1 or 3 months. The overall association between antibiotic agent and mortality for US residents was not statistically significant at either 1 or 3 months $(P=.208$ and .174 , respectively) after adjusting for stratum of mortality risk.

\section{DISCUSSION}

We examined the different approaches to care of nursing home residents with lower respiratory tract infection in the United States and the Netherlands and found little evidence that specific choice of antibiotic therapy affects mortality. Despite our hypoth-
Table 1. Baseline Characteristics and Treatments of Dutch and uS Nursing Home Residents Who Received Antibiotics for Lower Respiratory Tract Infection (Percentage Unless Otherwise Noted)

\begin{tabular}{|c|c|c|c|}
\hline $\begin{array}{l}\text { Characteristics and } \\
\text { Treatments Received }\end{array}$ & $\begin{array}{l}\text { United States } \\
\qquad(n=806)\end{array}$ & $\begin{array}{l}\text { Netherlands } \\
(n=415)\end{array}$ & $P *$ \\
\hline \multicolumn{4}{|l|}{ Resident characteristics } \\
\hline \multicolumn{4}{|l|}{ Demographics } \\
\hline Age, year, mean (SD) & $86.1(7.1)$ & $84.5(6.2)$ & $<.001$ \\
\hline Female & 67.6 & 66.0 & .57 \\
\hline \multicolumn{4}{|l|}{ Complete dependence at the time of diagnosist } \\
\hline Dressing & 46.5 & 82.1 & $<.001$ \\
\hline Eating & 28.0 & 55.1 & $<.001$ \\
\hline Mobility & 60.9 & 60.1 & .78 \\
\hline \multicolumn{4}{|l|}{ Illness signs and symptoms } \\
\hline Cough & 83.8 & 76.1 & .001 \\
\hline Decreased alertness & 27.6 & 42.0 & $<.001$ \\
\hline New or increased confusion & 9.6 & 8.6 & .61 \\
\hline $\begin{array}{l}\text { Physical findings on lung examination } \\
\text { compatible with pneumonia or other } \\
\text { lower respiratory tract infection }\end{array}$ & 81.3 & 97.3 & $<.001$ \\
\hline Pulse, beats per minute, mean (SD) & $87.6(17.2)$ & $92.5(16.9)$ & $<.001$ \\
\hline Purulent sputum & 25.6 & 32.7 & .012 \\
\hline Respiratory difficulty & 23.4 & 55.9 & $<.001$ \\
\hline Respiratory rate, breaths per minute, mean (SD) & $26.8(7.0)$ & $26.7(8.9)$ & .78 \\
\hline Temperature, ${ }^{\circ} \mathrm{C}$, mean (SD) & $37.6(0.9)$ & $38.5(0.9)$ & $<.001$ \\
\hline \multicolumn{4}{|l|}{ Comorbidities and conditions } \\
\hline Congestive heart failure & 32.6 & 17.9 & $<.001$ \\
\hline Chronic obstructive pulmonary disease & 20.2 & 15.7 & .057 \\
\hline Decubitus ulcers & 8.8 & 13.0 & .02 \\
\hline Dehydration present & 20.9 & 34.7 & $<.001$ \\
\hline Diabetes mellitus & 19.4 & 16.2 & .18 \\
\hline Parkinson disease & 9.9 & 7.5 & .16 \\
\hline Severe dementia & 25.2 & 51.1 & $<.001$ \\
\hline Beds in facility, $N$, mean (SD) & $152.0(115.2)$ & $219.1(58.2)$ & $<.001$ \\
\hline \multicolumn{4}{|l|}{ Treatments received } \\
\hline Antibiotic & & & $<.001$ \\
\hline Oral amoxicillin & 11.3 & 51.1 & \\
\hline Oral amoxicillin/clavulanate & 4.0 & 20.7 & \\
\hline $\begin{array}{l}\text { Oral doxycycline, tetracycline, macrolide, or } \\
\text { trimethoprim-sulfamethoxazole }\end{array}$ & 27.8 & 13.5 & \\
\hline $\begin{array}{l}\text { Intramuscular ampicillin or amoxicillin, } \\
\text { followed by oral amoxicillin }\end{array}$ & 0.0 & 11.1 & \\
\hline Fluoroquinolone, with or without another agent ${ }^{\ddagger}$ & 13.3 & 1.4 & \\
\hline $\begin{array}{l}\text { First-generation or oral second-generation } \\
\text { cephalosporin }{ }^{\ddagger}\end{array}$ & 11.3 & 0.5 & \\
\hline $\begin{array}{l}\text { Parenteral second-generation or third-generation } \\
\text { cephalosporin }{ }^{\ddagger}\end{array}$ & 18.2 & 1.2 & \\
\hline Other antibiotic regimens ${ }^{\ddagger}$ & 14.1 & 0.5 & \\
\hline \multicolumn{4}{|l|}{ Route of antibiotic administration } \\
\hline Oral only & 67.9 & 87.2 & $<.001$ \\
\hline Intramuscular§ & 12.4 & 11.8 & .76 \\
\hline Intravenous§ & 20.2 & 1.0 & $<.001$ \\
\hline Hospitalization & 30.4 & 0.2 & $<.001$ \\
\hline Rehydration therapy & 34.5 & 3.0 & $<.001$ \\
\hline \multicolumn{4}{|c|}{$\begin{array}{l}\text { * US-Dutch comparison, } \chi^{2} \text { probability for discrete variables, } t \text { test probability for continuous variables. } \\
\text { † A score of } 0 \text { represents independence, } 1 \text {, some to moderate dependence, and } 2 \text {, complete dependence. } \\
\text { † Because of small numbers, these categories were combined for analysis of Dutch residents. } \\
\S \text { Four US residents received antibiotics, both intramuscularly and intravenously, making the sum of the percentages } \\
\text { exceed } 100 \% \text {. }\end{array}$} \\
\hline
\end{tabular}


Table 2. Logistic Regression Models for 1- and 3-Month Mortality for Dutch and US Residents with Lower Respiratory Tract Infections

\begin{tabular}{|c|c|c|c|c|}
\hline \multirow[b]{2}{*}{ Variable } & \multicolumn{2}{|c|}{ 1-Month Mortality } & \multicolumn{2}{|c|}{ 3-Month Mortality } \\
\hline & $\begin{array}{l}\text { Parameter } \\
\text { Estimate }\end{array}$ & $\begin{array}{l}\text { Odds Ratio } \\
(95 \% \mathrm{Cl})\end{array}$ & $\begin{array}{l}\text { Parameter } \\
\text { Estimate }\end{array}$ & $\begin{array}{l}\text { Odds Ratio } \\
(95 \% \mathrm{Cl})\end{array}$ \\
\hline Intercept & -7.020 & & -7.302 & \\
\hline Age* & 0.023 & $1.25(0.99-1.59)$ & 0.029 & $1.34(1.08-1.65)$ \\
\hline Bladder incontinence at time of diagnosis $^{\dagger}$ & & & 0.248 & $1.28(1.05-1.57)$ \\
\hline Congestive heart failure & & & 0.330 & $1.39(1.03-1.88)$ \\
\hline Decreased alertness & 0.465 & $1.59(1.15-2.20)$ & 0.375 & $1.46(1.09-1.94)$ \\
\hline Dehydrated & 0.488 & $1.63(1.17-2.27)$ & 0.452 & $1.57(1.16-2.12)$ \\
\hline Eating self-performance at time of diagnosis ${ }^{\ddagger}$ & 0.442 & $1.56(1.21-2.00)$ & 0.314 & $1.37(1.09-1.71)$ \\
\hline Facility has 300 or more beds & 0.515 & $1.67(1.01-2.76)$ & & \\
\hline Male & 0.576 & $1.78(1.27-2.49)$ & 0.731 & $2.08(1.54-2.79)$ \\
\hline Walking self-performance at diagnosis & & & 0.398 & $1.49(1.14-1.95)$ \\
\hline Walking self-performance at diagnosis, squared & 0.193 & $1.21(1.07-1.37)$ & & \\
\hline New or increased cough & -0.536 & $0.58(0.41-0.84)$ & -0.497 & $0.61(0.44-0.85)$ \\
\hline Parkinson's disease & 0.596 & $1.81(1.11-2.97)$ & 0.477 & $1.61(1.03-2.52)$ \\
\hline Pulse* & 0.021 & $1.24(1.13-1.36)$ & 0.015 & $1.16(1.07-1.26)$ \\
\hline Respiratory distress & 0.781 & $2.18(1.59-3.00)$ & 0.469 & $1.60(1.20-2.13)$ \\
\hline Respiratory rate* & & & 0.016 & $1.17(0.97-1.43)$ \\
\hline C statistic & 0.765 & & 0.737 & \\
\hline Hosmer-Lemeshow goodness-of-fit statistic, $P \S$ & 0.90 & & 0.64 & \\
\hline \multicolumn{5}{|l|}{$\mathrm{Cl}=$ confidence interval. } \\
\hline \multicolumn{5}{|c|}{$\begin{array}{l}\text { * The odds ratios shown for age, pulse, and respiratory rate are for } 10 \text {-unit change. } \\
\dagger \text { Coding for bladder incontinence is as follows: } 1=\text { continent, } 2=\text { usually continent, } 3=\text { incontinent } 2 \text { or more times a week. } \\
\text { ‡ Coding for eating dependency is as follows: } 0=\text { independent, } 1=\text { requires assistance, } 2=\text { fully dependent. } \\
\S \text { A nonsignificant } P \text { value indicates good fit over the range of mortality risk. }\end{array}$} \\
\hline
\end{tabular}

esis, we also could not identify specific risk strata in which more aggressive antibiotic therapy appeared to result in better mortality outcomes. Based on their characteristics, the Dutch residents appeared to be much sicker and had higher unadjusted mortality. Nonetheless, the variable representing Dutch nationality was not significant in either mortality model. This finding indicates that mortality differences were mostly explained by case-mix and allowed us to substantially control for the differences between these 2 populations. We found no clear advantage for treatment with any particular antibiotic regimen after stratification by illness severity. At high-mortality risk, however, 1 month mortality for US residents was overestimated by the logistic model, and conversely, underestimated for Dutch residents (Figure 2). This difference was not evident at 3 months. These findings are consistent with some short-term increased survival associated with the more aggressive therapy observed in the United States that included more frequent use of parenteral antibiotics, multiple antibiotic regimens, and hospitalization. Even so, we cannot exclude some other difference between the populations as the explanation.

Whether short-term increased survival is of potential benefit is open to question. For residents with advanced dementia, who are facing a high 6-month mortality and the frequent necessity of restraints to prevent removal of intravenous lines, the benefit of such aggressive care

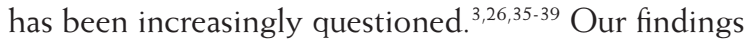
lend further support to this position because aggressive care appeared to offer little survival benefit in the 3 months after lower respiratory tract illness. Previous analysis of Missouri LRI Study data found no difference in 1-month mortality between residents first treated in the nursing home or the hospital, after adjusting for illness severity and probability of hospitalization. ${ }^{40}$

The study's main limitation is the universal problem with observational studies-we were unable to assure adequate control for confounding. Across levels of illness severity and between the 2 countries, residents received very different therapies, making it difficult to compare outcomes. Furthermore, the great number of regimens made comparisons difficult. Despite the absence of patterns suggesting agents with clear benefit or harm, a much larger study would be needed to provide adequate numbers in all categories of antibiotics and mortality risk.

Different study procedures and differences in the practice of medicine between the two nations could have affected results. Variables could not be used if they were not present in both studies, which forced us to omit some potent risk factors from the original 
studies, such as body mass index ${ }^{22}$ and resident discomfort. ${ }^{23}$ In the Missouri LRI Study, project nurses actively attempted to identify potential cases, while in the Dutch Pneumonia Study, nursing home physicians included residents when they diagnosed pneumonia. The physicians may have preferentially included the more definitive cases. To make study subjects comparable, we used a common case definition to select residents, and our logistic models performed well in adjusting for differences in mortality risk.

Ultimately, studies involving direct experimental comparisons between antibiotic agents are needed to determine the best treatments for lower respiratory tract infection acquired by nursing home residents. This article may help to provide a basis on which such a study could be ethically justified, because differences in illness severity are likely much more strongly related to mortality than differences in antibiotic treatments. Nonetheless, in the interim, the lack of benefit in 3-month survival found for more aggressive treatment lends support for treating nursing home residents in the nursing home with simpler regimens that involve less discomfort.

To read or post commentaries in response to this article, see it online at http://www. annfammed.org/cgi/content/full/3/5/422.

Key words: Nursing homes; aged; respiratory tract infections; pneumonia; anti-bacterial agents; delivery of health care; health services research

Submitted December 16, 2004; submitted, revised, March 4 2005; accepted April 4, 2005.

Funding support: This study was supported by a grant from the National Institute on Aging, grant number AG18335. The original data collection in Missouri was supported by the Agency for Healthcare Research and Quality, grant number HSO8551, and a Generalist Physician Faculty Scholars Award to Dr. Mehr from the Robert Wood Johnson Foundation. The original data collection in the Netherlands was supported by grants from Dutch Ministry of Health, Welfare and Sport (VWS, grant numbers 37851, 37852, 37853, and 37832) and the Society 'Het Zonnehuis.'
Figure 2. Predicted and actual 1- and 3-month mortality, by decile of predicted mortality risk for US and Dutch residents.

A. One month

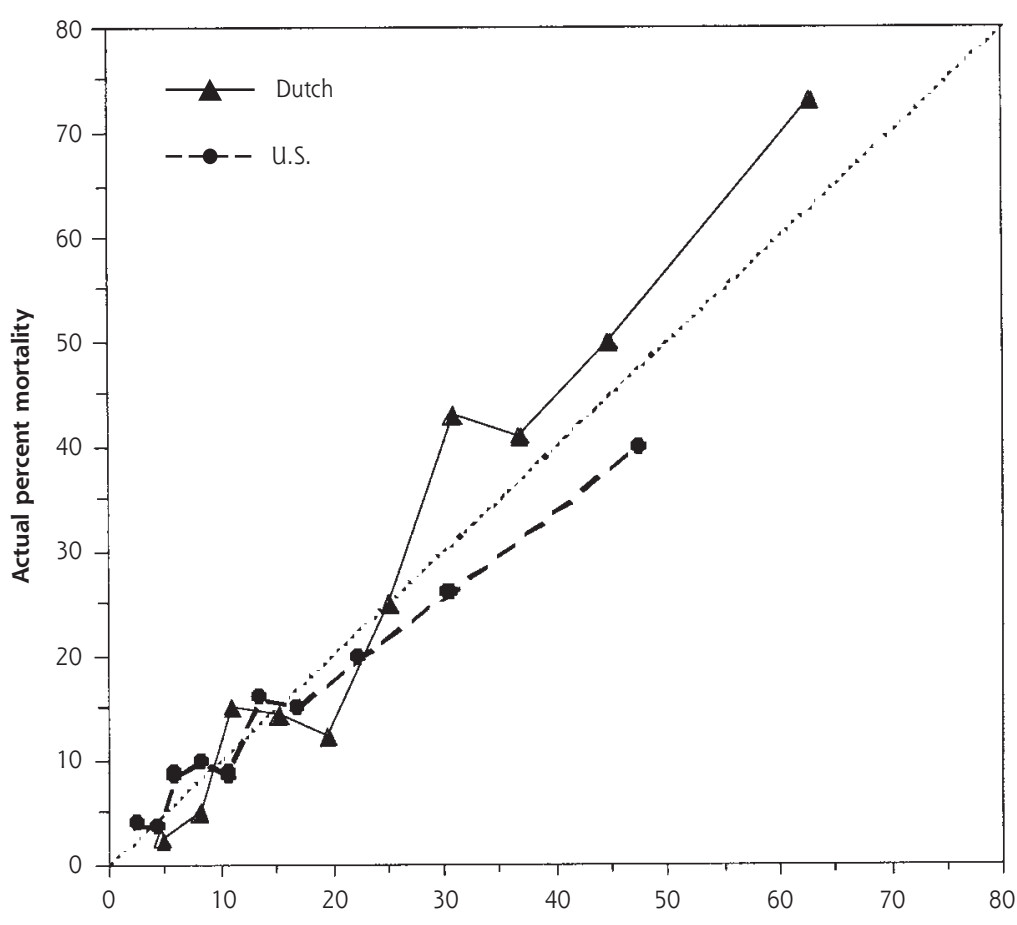

B. Three months

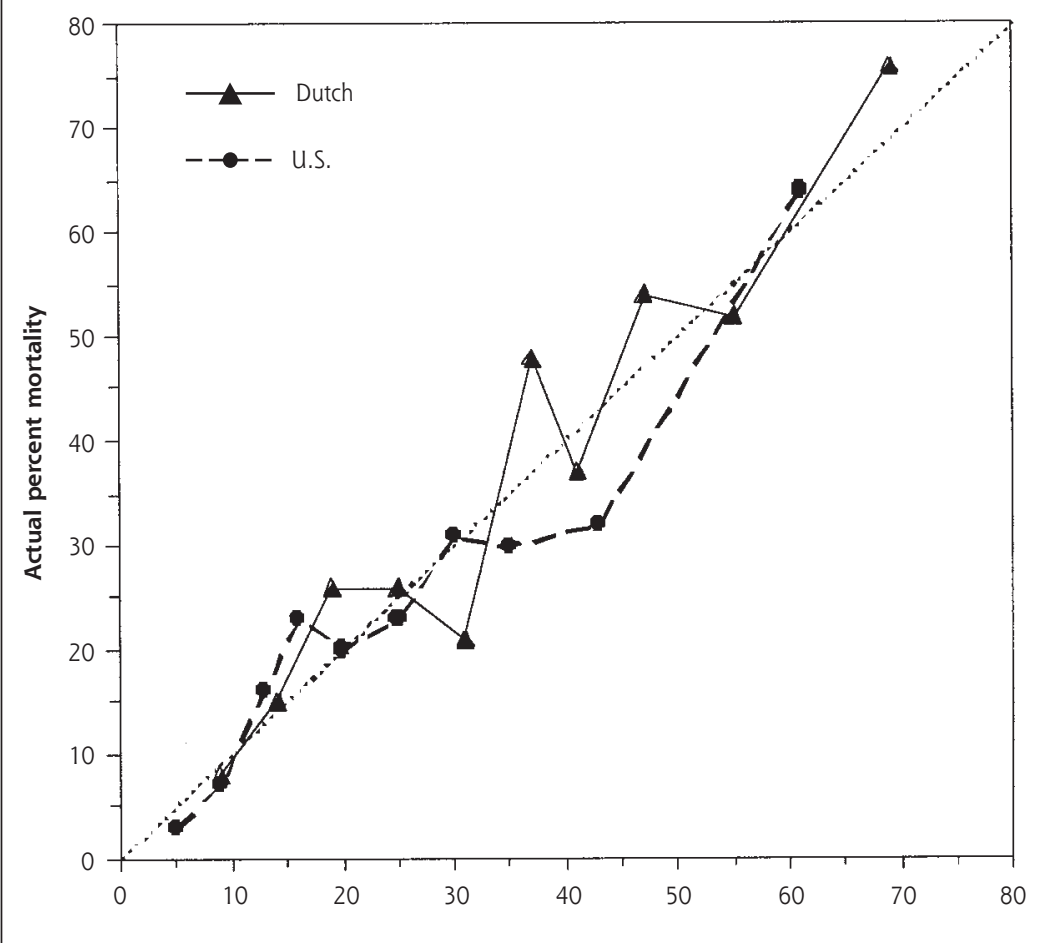

The dotted line indicates ideal discrimination, where predicted and actual mortality are equal. 


\section{References}

1. Jackson MM, Fierer J, Barrett-Connor $E$, et al. Intensive surveillance for infections in a three-year study of nursing home patients. Am J Epidemiol. 1992;135:685-696.

2. Murtaugh CM, Freiman MP. Nursing home residents at risk of hospitalization and the characteristics of their hospital stays. Gerontologist. 1995;35:35-43.

3. Muder RR, Brennen C, Swenson DL, Wagener M. Pneumonia in a long-term care facility. A prospective study of outcome. Arch Intern Med. 1996;156:2365-2370

4. Houston MS, Silverstein MD, Suman VJ. Risk factors for 30-day mortality in elderly patients with lower respiratory tract infection. Community-based study. Arch Intern Med. 1997;157:2190-2195.

5. Loeb M, McGeer A, McArthur M, Walter S, Simor AE. Risk factors for pneumonia and other lower respiratory tract infections in elderly residents of long-term care facilities. Arch Intern Med. 1999; 159:2058-2064.

6. Degelau J, Guay D, Straub K, Luxenberg MG. Effectiveness of oral antibiotic treatment in nursing home-acquired pneumonia. J Am Geriatr Soc. 1995;43:245-251.

7. Thompson RS, Hall NK, Szpiech M, Reisenberg LA. Treatments and outcomes of nursing-home-acquired pneumonia. J Am Board Fam Pract. 1997; 10:82-87.

8. Mehr DR, Zweig SC, Kruse RL, et al. Mortality from lower respiratory infection in nursing home residents. A pilot prospective communitybased study. J Fam Pract. 1998;47:298-304.

9. Naughton BJ, Mylotte JM, Tayara A. Outcome of nursing homeacquired pneumonia: derivation and application of a practical model to predict 30 day mortality. J Am Geriatr Soc. 2000;48:1292-1299.

10. Medina-Walpole AM, McCormick WC. Provider practice patterns in nursing home-acquired pneumonia. J Am Geriatr Soc. 1998;46: 187-192.

11. Nicolle LE, Strausbaugh LJ, Garibaldi RA. Infections and antibiotic resistance in nursing homes. Clin Microbiol Rev. 1996;9:1-17.

12. Fang GD, Fine $M$, Orloff J, et al. New and emerging etiologies for community-acquired pneumonia with implications for therapy. A prospective multicenter study of 359 cases. Medicine (Baltimore). 1990:69:307-316.

13. Hutt E, Kramer AM. Evidence-based guidelines for management of nursing home-acquired pneumonia. J Fam Pract. 2002;51:709-716.

14. Niederman MS, Mandell LA, Anzueto A, et al. Guidelines for the management of adults with community-acquired pneumonia. Diagnosis, assessment of severity, antimicrobial therapy, and prevention. Am J Respir Crit Care Med. 2001;163:1730-1754.

15. Mandell LA, Bartlett JG, Dowell SF, et al. Update of practice guidelines for the management of community-acquired pneumonia in immunocompetent adults. Clin Infect Dis. 2003;37:1405-1433.

16. Naughton BJ, Mylotte JM. Treatment guideline for nursing homeacquired pneumonia based on community practice. J Am Geriatr Soc. 2000;48:82-88.

17. Naughton BJ, Mylotte JM, Ramadan F, Karuza J, Priore RL. Antibiotic use, hospital admissions, and mortality before and after implementing guidelines for nursing home-acquired pneumonia. J Am Geriatr Soc. 2001;49:1020-1024

18. Peterson PK, Stein D, Guay DR, et al. Prospective study of lower respiratory tract infections in an extended-care nursing home program: potential role of oral ciprofloxacin. Am J Med. 1988;85:164-171.

19. Hirata-Dulas CA, Stein DJ, Guay DR, Gruninger RP, Peterson PK. A randomized study of ciprofloxacin versus ceftriaxone in the treatment of nursing home-acquired lower respiratory tract infections. J Am Geriatr Soc. 1991;39:979-985.
20. Mangi RJ, Peccerillo KM, Ryan J, et al. Cefoperazone versus ceftriaxone monotherapy of nosocomial pneumonia. Diagn Microbiol Infect Dis. 1992;15:441-447.

21. Phillips SL, Branaman-Phillips J. The use of intramuscular cefoperazone versus intramuscular ceftriaxone in patients with nursing homeacquired pneumonia. J Am Geriatr Soc. 1993;41:1071-1074.

22. Mehr DR, Binder EF, Kruse RL, et al. Predicting mortality in nursing home residents with lower respiratory tract infection: The Missouri LRI Study. JAMA. 2001;286:2427-2436.

23. van der Steen JT, Ooms ME, van der WAL G. Ribbe MW. Withholding or starting antibiotic treatment in patients with dementia and pneumonia: prediction of mortality with physicians' judgment of illness severity and with specific prognostic models. Med Decis Making. 2005;25:210-221.

24. Irvine PW, Van Buren N, Crossley K. Causes for hospitalization of nursing home residents: the role of infection. J Am Geriatr Soc. 1984:32:103-107.

25. Fried TR, Gillick MR, Lipsitz LA. Short-term functional outcomes of long-term care residents with pneumonia treated with and without hospital transfer. J Am Geriatr Soc. 1997;45:302-306.

26. van der Steen JT, Kruse RL, Ooms ME, et al. Treatment of nursing home residents with dementia and lower respiratory tract infection in the United States and The Netherlands: an ocean apart. J Am Geriatr Soc. 2004;52:691-699.

27. Mehr DR, Binder EF, Kruse RL, et al. Clinical findings associated with radiographic pneumonia in nursing home residents. J Fam Pract. 2001;50:931-937.

28. Hoek JF, Penninx BW, Ligthart GJ, Ribbe MW. Health care for older persons, a country profile: The Netherlands. J Am Geriatr Soc. 2000;48:214-217.

29. van der Steen JT, Ooms ME, Ader HJ, Ribbe MW, van der Wal G. Withholding antibiotic treatment in pneumonia patients with dementia: a quantitative observational study. Arch Intern Med. 2002;162:1753-1760.

30. Mehr DR, van der Steen JT, Kruse RL, et al. Lower respiratory infections in nursing home residents with dementia: a tale of two countries. Gerontologist. 2003;43 Spec No 2:85-93.

31. Long Term Care Facility Resident Assessment Instrument (RAI) User's Manual: For Use With Version 2.0 of the Health Care Financing Administration's Minimum Data Set, Resident Assessment Protocols, and Utilization Guidelines. Washington, DC: Health Care Financing Administration; 1995.

32. Volicer L, Hurley AC, Lathi DC, Kowall NW. Measurement of severity in advanced Alzheimer's disease. J Gerontol. 1994;49:M223-226.

33. The SAS System for Windows, version 8.0. Cary, NC: SAS Institute, Inc; 1999.

34. Stokes ME, Davis CS, Koch G. Categorical Data Analysis Using the SAS System. Cary, NC: The SAS Institute; 1995.

35. Volicer L, Collard A, Hurley A, et al. Impact of special care unit for patients with advanced Alzheimer's disease on patients' discomfort and costs. J Am Geriatr Soc. 1994;42:597-603.

36. Volicer L. Hospice care for dementia patients. J Am Geriatr Soc. 1997;45:1147-1149.

37. Morrison RS, Siu AL. Survival in end-stage dementia following acute illness. JAMA. 2000;284:47-52.

38. Brauner DJ, Muir JC, Sachs GA. Treating nondementia illnesses in patients with dementia. JAMA. 2000;283:3230-3235.

39. Volicer L. Management of severe Alzheimer's disease and end-of-life issues. Clin Geriatr Med. 2001;17:377-391.

40. Kruse RL, Mehr DR, Boles KE, et al. Does hospitalization impact survival after lower respiratory infection in nursing home residents? Med Care. 2004:42:860-870. 